\title{
Influence of the rhizosphere in a biopurification system on the dissipation of a pesticide mixture
}

\author{
C. Urrutia ${ }^{1}$, O. Rubilar ${ }^{2}$, G. Tortella ${ }^{2}$, J. M. Castillo ${ }^{4}$, E. Romero ${ }^{4}$, R. Azcón ${ }^{5}$, M. del P. Castillo ${ }^{6}$, \\ M. C. Diez ${ }^{2,3 *}$
}

${ }^{1}$ Doctoral Program in Sciences of Natural Resources, Universidad de La Frontera, Temuco, Chile. ${ }^{2}$ Scientific and Technological Bioresource Nucleus, Universidad de La Frontera, Temuco, Chile. ${ }^{3}$ Department of Chemical Engineering, Universidad de La Frontera, Temuco, Chile. ${ }^{4}$ Department of Environmental Protection, Estación Experimental del Zaidin. Consejo Superior de Investigaciones Cientificas (EEZCSIC), C/ Profesor Albareda 1, 18008-Granada, Spain. ${ }^{5}$ Department of Soil Microbiology and Symbiotic Systems, Estación Experimental del Zaidin. Consejo Superior de Investigaciones Cientificas (EEZ-CSIC), C/ Profesor Albareda 1, 18008-Granada, Spain. ${ }^{6}$ JTI-Swedish Institute of Agricultural and Enviromental Engineering, Box 7033, SE-75007 Uppsala, Sweden. ${ }^{*}$ Corresponding author: cristina.diez@ufrontera.cl

\begin{abstract}
In a biopurification system such as a biobed, the rhizosphere of the grass layer may be a significant factor for promoting pesticide dissipation in the biomixture. The rhizosphere effect of a Lolium perenne, Festuca arundinacea and Trifolium repens mixture on the dissipation of a pesticide combination that was composed of atrazine, chlorpyrifos and isoproturon was studied. The assay was performed using glass pots divided into two separate compartments (root surface and root-free), each filled with an organic biomixture (oat husk, top soil and peat) and contaminated with the pesticide mixture at $5 \mathrm{mg} \mathrm{kg}^{-1}$. Non-planted and noncontaminated pots were also used as controls. The results indicated that there were high atrazine, chlorpyrifos and isoproturon dissipation in the planted pots compared with the unplanted pots. An inverse correlation was found throughout the assay between phenoloxidase activity and residual pesticide ( $r=0.684$ to 0.952 ). Indeed, fungal biomass was positively correlated with phenoloxidase activity on day $1(\mathrm{r}=0.825)$ and day 30 $(\mathrm{r}=0.855)$. Besides, exudation of oxalic and malic acid in contaminated pots was higher than in the control without pesticides, associated with oxidation of the pesticide mixture in the biomixture of a bioded system. Therefore, the grass layer enhances pesticide removal in biobeds.
\end{abstract}

Keywords: Rhizosphere, pesticide dissipation, biopurification, phenoloxidase 


\section{Introduction}

The rhizosphere can be described as the zone of soil around plant roots whereby soil properties are influenced by the presence and activity of the root (Neumann et al., 2009). Because the rhizosphere continuously provides important sources of nutrients through root exudates, microbiological activity in this zone is up to four-fold greater than in soil further away from plant, resulting in a zone with higher metabolic capacities for microbiological action against both organic matter and contaminants (Haichar et al., 2008).

A reported mechanism used by rhizosphere microorganisms to take up contaminants by biosurfactant production, which facilitates contaminant degradation, mainly of hydrophobic compounds, and concomitantly increases their availability to plants (Read et al., 2003). In this context, plant species and soil are reportedly jointly responsible for the structure and function of microbial diversity in the rhizosphere (Berg and Smalla, 2009). Plants and their associated rhizosphere microorganisms, therefore, make an important contribution to contaminant degradation in soil (Wang and Oyaizu, 2009), and their use in onfarm biopurification systems, such as biobeds, can provide huge benefits.

A biobed is a biopurification system used to minimize point source contamination by pesticides. Its main component is an organic biomixture in which the pesticides are degraded, which is composed of straw, soil and peat $\left(2: 1: 1 \mathrm{vv}^{-1}\right)$ (Castillo et al., 2008). Generally, a layer of grass is grown on top of the biobed, which retains moisture in the biomixture and reveals pesticide spillages. However, the rhizosphere of this grass layer and its associated microorganisms could make an important contribution to improving the pesticide degradation in the biopurification system; to date this potential has not been considered in depth in biobed studies. An important step is to identify the plant species that are capable of surviving a particular toxic contamination level in the biobed system. Plant species with fibrous rooting systems, such as Lolium perenne, Festuca arundinacea and Agrostis tenuis, have demonstrated great potential for removing contaminants because they provide a large root surface area that interacts with soil microorganisms in biodegradation. Lolium multiflorum can increase atrazine, chlorpyrifos and pentachlorophenol removal (He et al., 2008; Merini et al., 2009; Urrutia et al., 2013a). Singh et al. (2004) demonstrated that the Pennisetum clandestinum rhizosphere tolerated atrazine and simazine and improved their degradation compared with unplanted soil. In another work, Wang and Oyaizu (2009) evaluated the phytoremediation potential of four plant species for dibenzofuran-contaminated soil. The authors determined that Trifolium repens L. not only had the highest root biomass but also the highest numbers of dibenzofuran-degrading bacteria compared with three other grass species.

The aim of the present work was to evaluate the effect of the rhizosphere of a biopurification system on the dissipation of a pesticide mixture.

\section{Materials and Methods}

\subsection{Biomixture preparation}

The biomixture was prepared according to Urrutia et al. (2013b) using oat husk as the lignocellulosic material. It was prepared by mixing Andisol topsoil, commercial peat (43.7\% organic carbon) and oat husk $(\mathrm{OH})$ that was collected from crop residues $(36.7 \%$ 
organic carbon) in a proportion of 1:1:2 by volume. The soil (30.7\% sand, $41.8 \%$ silt, $27.4 \%$ clay, $6.4 \%$ organic carbon, $\mathrm{pH} 5.2$ ), which belonged to the Temuco series $\left(38^{\circ} 42^{\prime} \mathrm{S}, 73^{\circ} 35^{\prime} \mathrm{W}\right)$, was collected $(0-20 \mathrm{~cm}$ depth) and sieved $(3 \mathrm{~mm})$. The constituents were mixed vigorously to obtain a homogeneous biomixture, and moisture content was adjusted to $60 \%$ of the water holding capacity (WHC) by adding distilled water. The biomixture was placed in polypropylene bags for maturation and stored in the dark at $20 \pm 2{ }^{\circ} \mathrm{C}$ for 40 days before it was used in the experiments.

\subsection{Experimental design}

Glass pots of $18 \times 17 \times 9 \mathrm{~cm}$ (length $\mathrm{x}$ width $\mathrm{x}$ height) were used in this experiment. The pots were divided into a root compartment (RC) $(6 \mathrm{~cm}$ in width) and a root-free compartment (RFC) $(3 \mathrm{~cm}$ in width) and were separated by nylon mesh $(25 \mu \mathrm{m})$. The design successfully prevented root hairs from entering adjacent zones and also kept the zones separated while allowing the transfer of microorganisms and root exudates between the compartments. In total, one hundred and forty grams of biomixture were used to fill the pots. The RC contained one hundred Lolium perenne, Festuca arundinacea and Trifolium repens seeds in a proportion of 50, 45 and 5\%, respectively. The seeds were sown in the biomixture and covered with a layer of soil $(2 \mathrm{~g})$. The biomixture was maintained at $60 \%$ water holding capacity under greenhouse conditions $\left(22 \pm 3 / 18 \pm 3^{\circ} \mathrm{C}\right.$ day/night temperatures; $16 / 8 \mathrm{~h}$ light/dark photoperiod; 60 $70 \%$ relative humidity) for 30 days. The pots were then contaminated with a mixture of atrazine (ATZ), isoproturon (ISP) and chlorpyrifos (CHL) in aqueous solution to reach a concentration of $5 \mathrm{mg} \mathrm{kg}^{-1}$ of each pesticide (root compartment $(\mathrm{RC}+\mathrm{P})$ and root-free compartment $(\mathrm{RFC}+\mathrm{P})$ ). Non-contaminated pots (root compartment (RC-P) and root-free compartments (RFC-P)) and unplanted pots (contaminated $(\mathrm{C}+\mathrm{P})$ and non-contaminated (C-P)) were used as controls. In total, three replicates were performed for each treatment.

The pots were arranged in a randomized design. On days 1,15 and 30 after pesticide application, pesticide concentration, enzyme activities ( $\beta$-glucosidase and phenoloxidase) and total bacteria and fungi abundance were measured in the biomixture of the different pot compartments. The grass layer root exudates (oxalic acid, malic acid, citric acid and succinic acid) were also measured.

\subsection{Analytic procedure}

\subsubsection{Extraction and pesticide analysis}

Residual pesticides were extracted from biomixtures (5 g dry weight (dw)) by shaking (1 h, $250 \mathrm{rpm}$ ) with $20 \mathrm{~mL}$ of acetone and ultrasonication $(30 \mathrm{~min})$. After centrifuging (10,000 rpm), $5 \mathrm{~mL}$ of the supernatant was collected, filtered with a polytetrafluoroethylene (PTFE) membrane (0.2- $\mu \mathrm{m}$ pore size; Millipore), evaporated with fluxed $\mathrm{N}_{2}$ to dryness, and dissolved in $1 \mathrm{~mL}$ of acetonitrile:water. Pesticide concentrations were determined by high-performance liquid chromatography (HPLC).

ATZ, CHL, and ISP concentrations were determined by HPLC (Agilent Series 1100, Böblingen, Germany) that had been equipped with a diode array detector. A $150 \mathrm{~mm}$ x $2.1 \mathrm{~mm}$ i.d. Zorbax Rx-C8 analytical column and a $12.5 \mathrm{~mm}$ x $2.1 \mathrm{~mm}$ i.d. Eclipse XDB-C8 guard cartridge were used that had both been packed with diisopropyl n-octyl (5 mm). Eluent A (70\%) was Milli-Q water that had been adjusted to $\mathrm{pH} \mathrm{3}$, and eluent $\mathrm{B}$ was acetonitrile. The gradient condition used 
for separating the pesticides was 3 min $30 \% \mathrm{~B}, 4-5$ $\min 35 \% \mathrm{~B}, 6-8 \min 40 \% \mathrm{~B}, 9-13 \min 60 \% \mathrm{~B}, 14-22$ $\min 70 \% \mathrm{~B}$, and $23-32 \min 30 \% \mathrm{~B}$. The flow rate was constant at $0.2 \mathrm{~mL} \mathrm{~min}{ }^{-1}$. Column temperature was maintained at $30 \pm 1^{\circ} \mathrm{C}$. The detector was set at three wavelengths for data acquisition: 220, 245 and 288 $\mathrm{nm}$. Instrument calibrations and quantifications were performed against pure reference standards $(0.5-5 \mathrm{mg}$ $\left.\mathrm{L}^{-1}\right)$ for each compound. Recovery of ATZ, CHL and ISP was $>90 \%$.

\subsubsection{Enzyme activity analyses}

Phenoloxidase activity was assessed using the MBTH/DMAB method (adapted from Castillo et al (1994). Briefly, samples (10 g dw) of the biomixture were shaken (150 rpm, $2 \mathrm{~h}$ ) with $25 \mathrm{~mL}$ of a $100 \mathrm{mM}$ succinate-lactate buffer $(\mathrm{pH} 4.5)$. The samples were centrifuged $(4.000 \mathrm{rpm}, 20 \mathrm{~min})$. The supernatant of each sample was collected, filtered through a $0.45-\mu \mathrm{m}$ membrane and measured immediately. The reaction mixture contained $300 \mu \mathrm{L}$ of $6.6 \mathrm{mM}$ DMAB, $100 \mu \mathrm{L}$ of $1.4 \mathrm{mM}$ MBTH, $30 \mu \mathrm{L}$ of 20 $\mathrm{mM} \mathrm{MnSO}_{4}$ and $1560 \mu \mathrm{L}$ of the filtered sample. The reaction was observed in a Spectronic Genesis 2PC spectrophotometer at $590 \mathrm{~nm}\left({ }_{\varepsilon}=0.053 \mu \mathrm{M}^{-1} \mathrm{~cm}^{-1}\right)$. No correction was made for the possible presence of lignin peroxidase (LiP) and Laccase (Lac) activity. Thus, the measurement may represent the sum of manganese peroxidase (MnP), LiP and Lac activity but is expressed as phenoloxidase activity (Castillo and Torstensson, 2007).

$\beta$-glucosidase activity was analysed by determining the amount of p-nitrophenol (PNP) produced from 4-nitrophenyl- $\beta$-D glucanopyranoside (PNG) as described by Tabatabai (1982). Enzyme activity was determined in triplicate using $0.2 \mathrm{~g}$ of the biomixture sample.

\subsubsection{DNA extraction from the biomixture}

Total DNA was extracted from $250 \mathrm{mg}$ dw of each of the three samples taken from the biomixture of the pots. Each sample was mixed with a solution of $100 \mathrm{mM}$ Tris (pH 8.0), 100 mM EDTA (pH 8.0), 100 $\mathrm{mM} \mathrm{NaCl}$, and $2 \%\left(\mathrm{w} \mathrm{v}^{-1}\right)$ sodium dodecyl sulphate. Glass beads of different diameters were added in a bead-beater tube, and the biomixture solution was shaken for $30 \mathrm{~s}$ at 1,600 rpm in a mini bead-beater cell disruptor (Mikro-Dismembrator; S.B. Braun Biotech International) before centrifuging at 12,235 rpm for 1 min. For protein precipitation, the supernatants were incubated on ice for $10 \mathrm{~min}$ with a $1 / 10$ volume of $3 \mathrm{M}$ sodium acetate and centrifuged (12,235 rpm, $5 \mathrm{~min}$, $4^{\circ} \mathrm{C}$ ). In the last step, nucleic acids were precipitated from the supernatants by adding 1 volume of icecold isopropanol. For DNA purification, polyvinylpolypyrrolydone (PVPP, Sigma-Aldrich, USA) columns were used and were prepared by adding 92-95 mg (i.e., $1.2 \mathrm{~cm}$ ) of PVPP powder to MicroSpin Chromatography columns (Bio-Rad, USA). The tubes were centrifuged ( $2 \mathrm{~min}, 3,270 \mathrm{rpm}$ ) with 400 $\mu \mathrm{L}_{2} \mathrm{O}$. This procedure was repeated a second time. DNA extracts were then purified using PVPP columns (3,270 rpm, $\left.4 \mathrm{~min}, 10^{\circ} \mathrm{C}\right)$ (Petric et al., 2011).

\subsubsection{Real-Time PCR Quantification (Q-PCR) of bacteria and fungi}

Total bacteria and fungi abundance in the biomixture was quantified using small ribosomal subunit $16 \mathrm{~S}$ and 18Sr RNA genes. For this purpose, the primer sets 341F 5'-CCTACGGGAGGCAGCAG-3',518R 5'-ATTACCGCGGCTGCTGG-3' (Muyser et al, 1993) and FR1 5'-A(I)CCATTCAATCGGTAXT-3', FF390 5'-CGATAACGAACGAGACCT-3' were (Vainio and Hantula, 2000) selected for bacteria and 
fungi, respectively. An assembly of $16 \mathrm{~S}$ rRNA and 18Sr RNA genes in pGEMT easy vector (Promega) plasmids using Pseudomonas putida KT2440 and Fusarium oxysporum JX910900, standard curves, and bacterial and fungal Q-PCR conditions were performed according to Castillo et al (2013). Reactions were conducted in an iCycler MyiQ ${ }^{\mathrm{TM}}$ System (Bio$\mathrm{rad}$, USA) using the SybrGreen ${ }^{\circledR}$ detection system. The reaction was performed in a final volume of 15 $\mu \mathrm{L}$ containing $7.5 \mu \mathrm{L} \mathrm{iQ}^{\mathrm{TM}} \mathrm{SYBR}{ }^{\circledR}$ Green Supermix, $0.5 \mu \mathrm{M}$ of each primer, $0.5 \mathrm{mg} \mathrm{mL}^{-1}$ bovine serum albumin (BSA) and $2 \mathrm{ng}$ of template DNA. The function values describe the relationship between the $\mathrm{Ct}$ (threshold cycle), and the sequence number of each bacteria and fungi are -3.28 and -3.10 , respectively, with a PCR efficiency of $101 \%$ and $109 \%$. Controls without templates gave null or negligible values.

\subsubsection{Extraction and root exudate analysis}

Organic acids were collected from the grass layer at 1 , 15 and 30 days. The roots were washed with distilled water and then placed in $50 \mathrm{~mL}$ of distilled water for $30 \mathrm{~min} ; 5 \mathrm{~mL}$ was filtered through a PTFE membrane $(0.2-\mu \mathrm{m}$ pore size, Millipore), and the organic acid concentration was determined by high-performance liquid chromatography (HPLC). Root exudates were standardized by root dry weight, which was measured immediately after treatment.

Oxalic acid, malic acid, citric acid and succinic acid concentrations were determined by HPLC using a Merck Hitachi L-7100 pump, a Rheodyne 7725 injector with a $20 \mu \mathrm{L}$ loop and a Merck Hitachi L-7455 diode array detector. Separation was performed using a C18 column (Purospher Star RP-C18e, $5 \mu \mathrm{m} 4.6$ x $150 \mathrm{~mm}$ ) with a guard column (LichroCART RP-C18e, $5 \mu \mathrm{m} 4$ x 4 mm). Eluent A was methanol, and eluent B was phosphate buffer. The gradient condition used for organic acid separation was $0-15 \mathrm{~min}$ of $7 \% \mathrm{~A}$. The flow rate was set

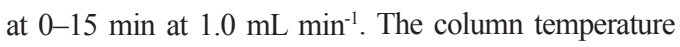
was maintained at $30 \pm 1{ }^{\circ} \mathrm{C}$. The detector was set at $210 \mathrm{~nm}$ for data acquisition. Instrument calibrations and quantifications were performed against pure reference standards (0.1-10 $\left.\mathrm{mg} \mathrm{L}^{-1}\right)$ for each compound. Recovery of each organic acid was $>90 \%$.

\subsubsection{Statistical data analysis}

The experiment was conducted with three independent replicates. The pesticide measurement, enzyme activities and size of the total bacterial and fungal community during the dissipation period were subjected to one-way ANOVA, and the averages were compared using the Tukey multiple range test at $p \leq 0.05$ to identify significant effects of different treatments on the same sampling day. Pearson correlations were used to assess the relationships between pesticides and phenoloxidase activity as well as the relationships between phenoloxidase activity and fungal biomass on days 1 and 30 . To estimate a possible change in root exudate organic acids caused by the pesticide addition in the planted pots, the data were compared (contaminated pots $(\mathrm{RC}+\mathrm{P})$ and noncontaminated pot (RC-P)) using Student's t-test.

\section{Results and Discussion}

\subsection{Dissipation of ATZ, CHL and ISP}

The effect of the rhizosphere on ATZ, CHL and ISP dissipation in the biomixtures of the biobed system is demonstrated in Figure $1 \mathrm{a}, \mathrm{b}$ and c. Generally, the grass layer increased the removal of the three pesticides. The data indicates a higher dissipation of the three pesticides in all sampling days in the $\mathrm{RC}+\mathrm{P}$ compartment. On sampling day 1 , the dissipation of ATZ, CHL and ISP in the RC+P compartment were $15.46,13.83$ and $25.55 \%$, respectively. Similar results 
were observed in the RFC+P compartment (12.85, 9.57 and $24.60 \%$, respectively, for ATZ, CHL and ISP dissipation). In contrast, the dissipation rates of ATZ, CHL and ISP in the unplanted pot $(\mathrm{C}+\mathrm{P})$ were $0,5.4$ and $3.9 \%$, respectively. Pesticide dissipation

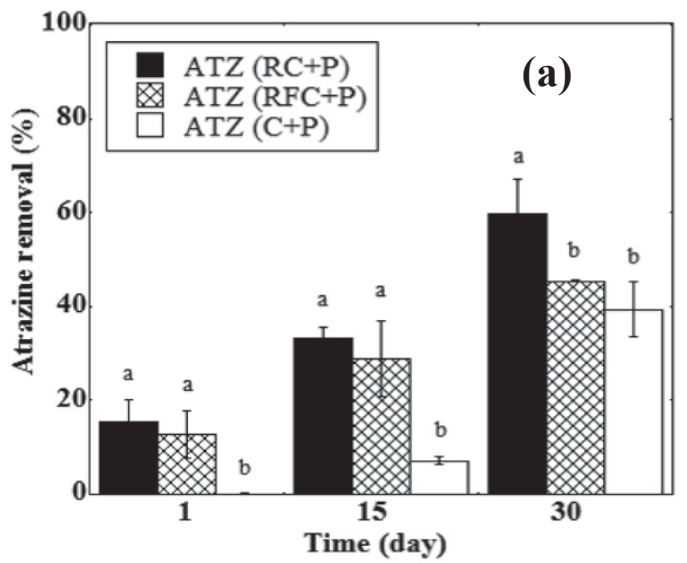

on day 15 was significantly higher $(p<0.05)$ in the $\mathrm{RC}+\mathrm{P}$ compartment compared with the unplanted $\mathrm{C}+\mathrm{P}$ treatment. At the end of the trial (30 days incubation), removal from the $\mathrm{RC}+\mathrm{P}$ compartment was higher than from the unplanted biomixture $(\mathrm{C}+\mathrm{P})$ by $20.3 \%, 24.4 \%$ and $22.35 \%$ for ATZ, CHL and ISP, respectively.

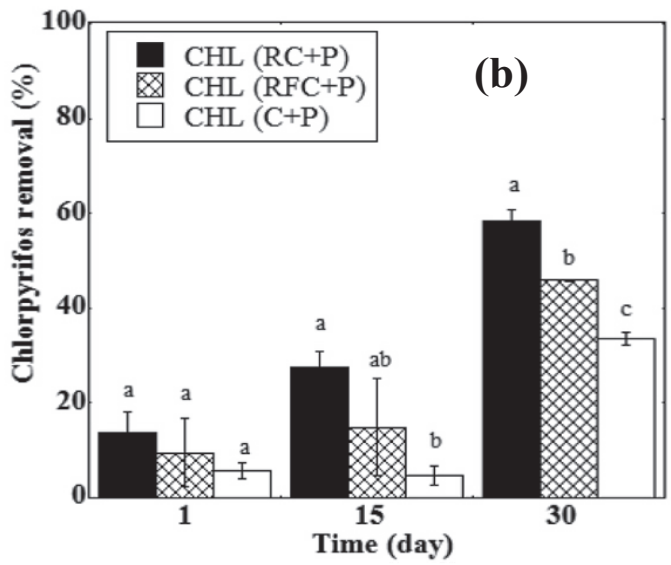

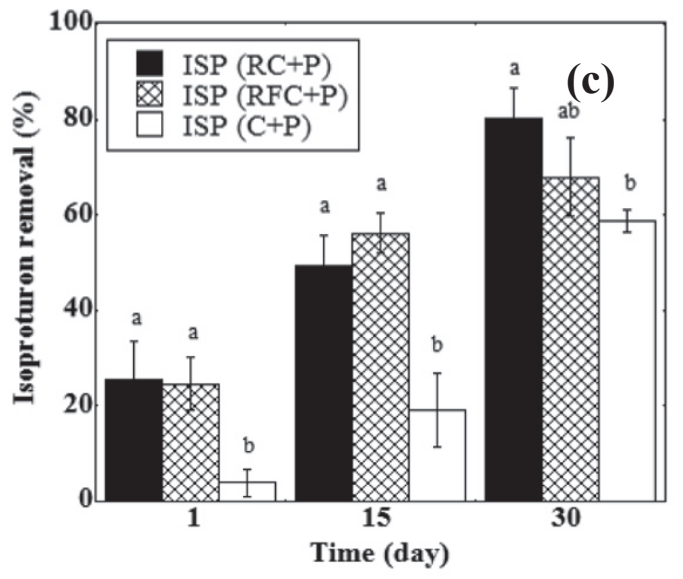

Figure 1. Pesticide removal (\%) after 1, 15 and $30 \mathrm{~d}$ for ATZ (a), CHL (b) and ISP (c) at $5 \mathrm{mg} \mathrm{kg}^{-1}$ in the biomixtures planted (root compartment $(\mathrm{RC}+\mathrm{P})$ and root-free compartment $(\mathrm{RFC}+\mathrm{P})$ ) and unplanted pots $(\mathrm{C}+\mathrm{P})$. Each value is the mean of three replicates with error bars showing the standard deviation of the mean. Different letters refer to significant differences in mean values among the different treatments of each pesticide 
These results agree with several reports demonstrating that the rhizosphere of tolerant plant species was effective in promoting the dissipation of different contaminants. The presence of mangrove roots improved phenanthrene and pyrene dissipation by $47.7 \%$ and $37.6 \%$, respectively, compared with unplanted treatment values of $26.2 \%$ and $22.8 \%$, respectively, after 60 days (Lu et al., 2001). In another work, Lolium multiflorum displayed a $20 \%$ higher atrazine removal capacity than bulk soil after 21 days of incubation (Merini et al., 2009). L. multiflorum likewise displayed high pentachlorophenol (PCP) removal $(>96 \%)$ in a planted rhizotron system compared with unplanted treatments in which PCP dissipation was approximately 36\% (Urrutia et al., 2013a).

Furthermore, dissipation of the three pesticides in the root-free compartment close to the rhizosphere $(\mathrm{RFC}+\mathrm{P})$ showed no-significant differences compared with the rhizosphere compartment $(\mathrm{RC}+\mathrm{P})$ at almost all assay times (Figure 1); this may demonstrate the influence of the root exudates in microbial composition and activity given that they are capable of degrading ATZ, CHL and ISP. Similar results were reported by $\mathrm{He}$ et al. (2005), who found higher pentachlorophenol degradation in the root compartment and the six separated compartments at various distances from the root surface of a planted rhizobox system compared with unplanted treatments. The authors attributed this finding to the beneficial effect on the degradation of root exudates and their interaction with microbial activity.

\subsection{Enzyme activity analysis}

$\beta$-glucosidase activity displayed different responses in planted and unplanted treatments (Figure 2a). Specifically, lower values were observed in the $\mathrm{C}+\mathrm{P}$ treatment for all days. Since, $\beta$-glucosidases are enzymes involved in the mineralization of organic materials as they catalyse the hydrolysis of terminations of the $\beta$-D-glucose chain releasing $\beta$-glucose that become available for microorganisms. This enzymatic activity can be considered a soil quality indicator, as it indicates changes in organic matter in the soil. Moreover, herbicide presence can decreases $\beta$-glucosidase activity, due to that microbial viability is affected (Moreno et al., 2011). However, plants significantly $(p<0.05)$ increased $\beta$-glucosidase activity, which was higher in the $\mathrm{RC}+\mathrm{P}$ and $\mathrm{RFC}+\mathrm{P}$ compartments than in the noncontaminated treatments on days 15 and 30 . In this context, Hernández-Allica et al. (2006) reported that higher $\beta$-glucosidase activity was observed in metalpolluted soil planted with Thlaspi caerulescens than in unplanted treatments. These results may be related to the organic compounds released by the plant roots, which enhance microbial biomass and activity.

The presence of plants in the different treatments likewise stimulated phenoloxidase activity, as demonstrated in Figure 2b. Phenoloxidase activity has been reported as the most important biological activity for contaminant degradation in soil (Briceño et al., 2007; Diez, 2010) and in the biomixture of the biobed system (Castillo et al., 2008). Our results demonstrated that both compartments of the contaminated pots $(\mathrm{RC}+\mathrm{P}$ and $\mathrm{RFC}+\mathrm{P})$ displayed a significant increase $(P<0.05)$ in phenoloxidase activity compared with unplanted treatments $(\mathrm{C}+\mathrm{P}$ and C-P) on days 1, 15 and 30. These results are in agreement with those of Lee et al. (2008), who observed that the presence of plant roots in soil contaminated with phenanthrene and pyrene (PAHs) increased the amount of peroxidase activity and PAH dissipation compared with unplanted pots.

Therefore, plant-microbe interactions in the fungicontaining root zone, including the formation of 
symbiotic mycorrhiza, may produce exoenzymes, such as peroxidases in the rhizosphere; these enzymes may play an important role in the detoxification of soil contaminants, as showed in our results. However, this effect varies with plant species as well as environmental factors such as the nutrient status of the matrix (Chaudhry et al., 2005).

A significant correlation was observed between phenoloxidase activity and residual pesticide concentration for all sampling days (Table 1). The residual concentrations of ATZ, CHL and ISP presented a negative correlation with phenoloxidase activity, with the correlation coefficient ranging from 0.684 to 0.952 . These values suggest that these enzymes may be involved in the dissipation of these pesticides. Castillo and Torstensson (2007) reported that the degradation of metamitron, chloridazon, isoproturon, and linuron was correlated with phenoloxidase activity in the biobed system biomixtures.
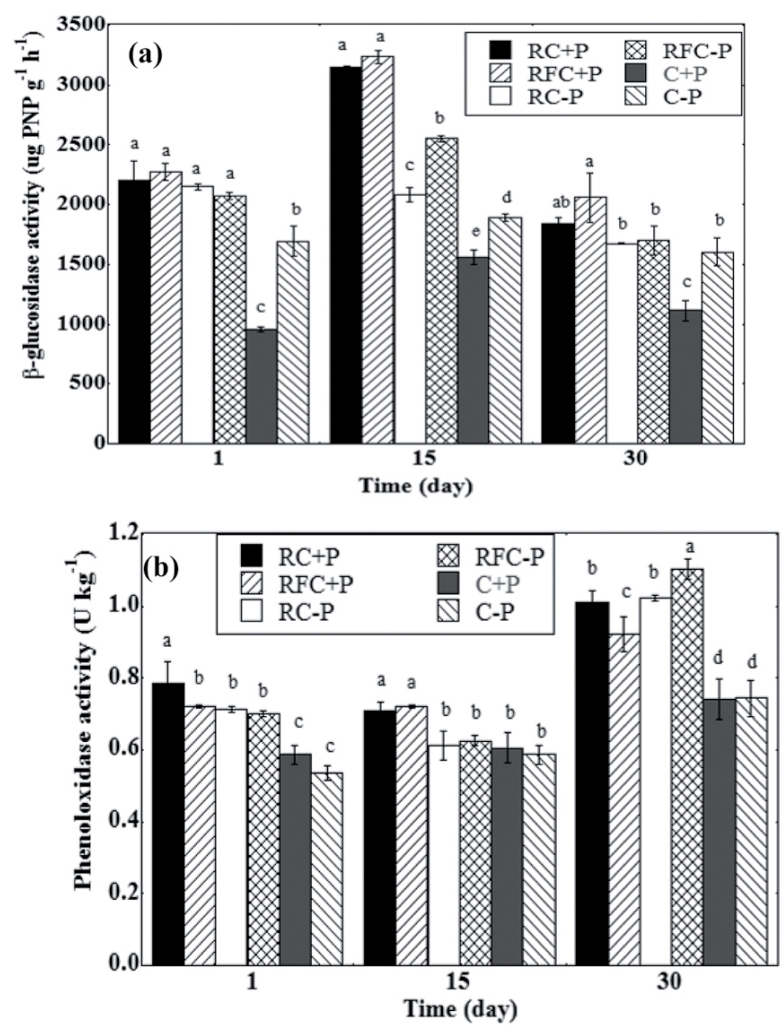

Figure 2. $\beta$-glucosidase activity (a), phenoloxidase activity (b) in the biomixture contaminated with $5 \mathrm{mg} \mathrm{kg}^{-1}$ concentrations of pesticides, in planted pots (root compartment $(\mathrm{RC}+\mathrm{P})$ and root- free compartment (RFC $+\mathrm{P})$ ) and unplanted pots $(\mathrm{C}+\mathrm{P})$. In addition, non-contaminated pots (root compartment (RC-P) and root- free compartment (RFC-P)) and unplanted pots (C-P) were used as controls during the incubation time. Each value is the mean of three replicates with error bars showing the standard deviation of the mean. Different letters refer to significant differences in the mean values among different treatments of each pesticide on the same day. 

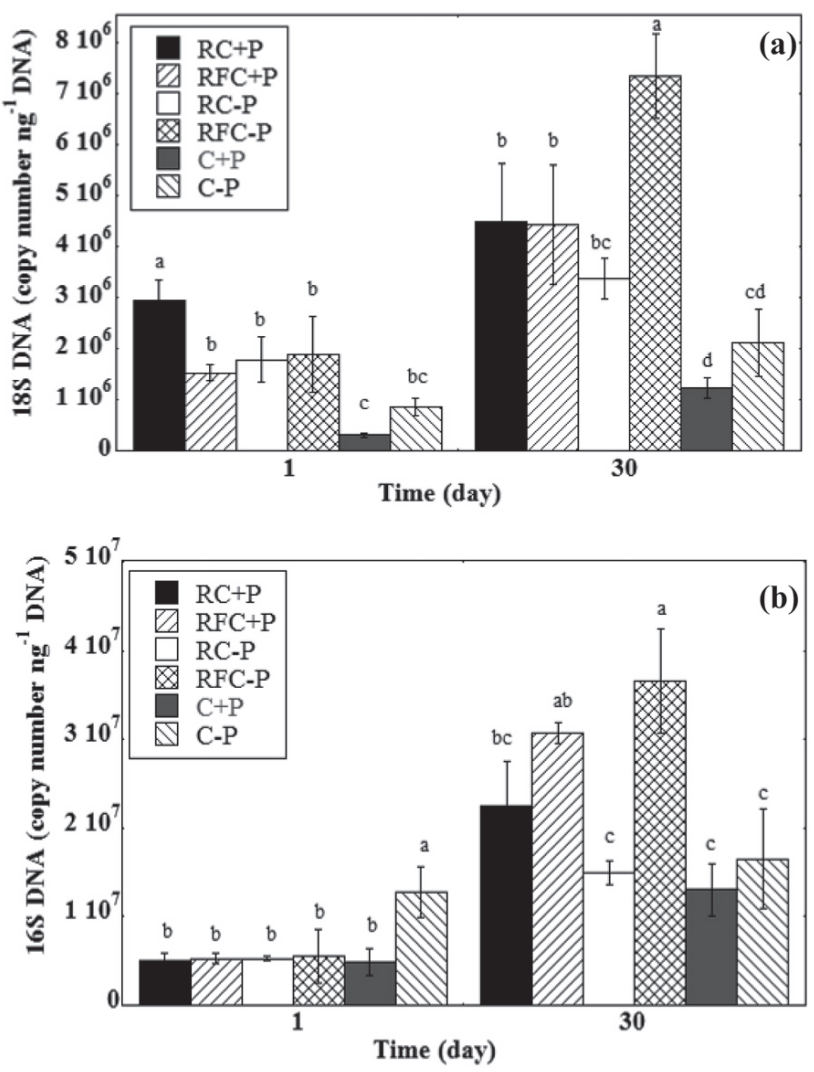

Figure 3. Estimation of the fungal (a) and bacterial (b) population size in the biomixtures contaminated with $5 \mathrm{mg} \mathrm{kg}^{-1}$ concentration of pesticides, in planted pots (root compartment $(\mathrm{RC}+\mathrm{P})$ and root- free compartment $(\mathrm{RFC}+\mathrm{P})$ ) and unplanted pots $(\mathrm{C}+\mathrm{P})$. In addition, non-contaminated pots (root compartment (RC-P) and root-free compartment (RFC-P)) and unplanted pots (C-P) were used as controls, during the incubation time. Each value is the mean of three replicates with error bars showing the standard deviation of the mean. Different letters refer to significant differences in mean values among different treatments of each pesticide on the same day.

\subsection{Real-Time PCR Quantification (Q-PCR) of bac-} teria and fungi

The fungal and bacterial populations were estimated by real-time PCR (Figure 3a and b). Fungal and bacterial gene copy numbers were increased in planted biomixtures compared with unplanted biomixtures on day 30 . The total fungal community was significantly larger $(p<0.05)$ in the biomixtures that were contaminated unplanted contaminated biomixtures $(\mathrm{C}+\mathrm{P})$ on days 1 and 30, displaying the same pesticide removal pattern observed previously in the contaminated treatments. In control treatments without pesticides, higher values were detected in planted treatments in both compartments compared with unplanted pots. The RFC-P compartment displayed a larger biomass $\left(7.34 \times 10^{6}\right.$ copy number ng-1 DNA) on day 30 , consistent with the high phenoloxidase activity detected on the same day. These results indicate that fungal biomass and activity were greatly increased in the biobed system biomixtures 
with a grass layer. Fungal population size was positively correlated with phenoloxidase activity on day $1(\mathrm{r}=0.825)$ and day $30(\mathrm{r}=0.855)$. The rhizosphere effect was therefore positive, favouring ATZ, CHL and ISP dissipation in the biomixtures. Conversely, bacterial community size in the planted pots on day 1 displayed no significant differences $(p<0.05)$, and only the C-P treatment size was higher. However, in planted pots (RC+P, RFC+P and RFC-P), the bacterial copy number was higher than in the other treatments on day 30. The increase in population size could have also contributed to higher pesticide dissipation compared with unplanted pots.

Our results are comparable with those of He et al. (2005), who reported that in a rhizobox system the planted treatments (root compartment) significantly increased microbial biomass, especially in the nearrhizosphere, which enhanced pentachlorophenol degradation in soil. These differences observed between soil with and without plants as well as among sampling zones in varying proximity to roots were expected on the basis of microbial growth and community structure modified by root exudates.

Table 1. Significant correlation between phenoloxidase activity and residual concentration of atrazine (ATZ), chlorpyrifos (CHL) and isoproturon (ISP) in the biobed biomixtures of different treatments.

\begin{tabular}{lclll}
\hline & $\begin{array}{l}\text { Time } \\
\text { (day) }\end{array}$ & ATZ & CHL & ISP \\
\hline Phenoloxidase & 1 & $-0.910^{* *}$ & $-0.691^{*}$ & $-0.882^{* *}$ \\
activity & 15 & $-0.878^{* *}$ & $-0.684^{*}$ & $-0.935^{* *}$ \\
& 30 & $-0.818 * *$ & $-0.952^{* *}$ & $-0.840^{* *}$ \\
\hline & \\
$*$ correlation is significant at the 0.05 level (bilateral) & \\
$*$ correlation is significant at the 0.01 level (bilateral) &
\end{tabular}

\subsection{Root exudate organic acids}

The range of organic acids exuded by roots varies by plants, but oxalic, benzoic, maleic, succinic, lactic, malic and citric acids were frequently observed in most plant species (Strobel, 2001). Figure 4 shown the oxalic acid, malic acid, citric acid and succinic acid exuded by roots of $L$. perenne, $F$. arundinacea and $T$. repens, which were planted in a proportion of 50,45 and $5 \%$, respectively. Overall, the four organic acids were detected in all of the sampling days, and oxalic acid and malic acid concentrations were higher in contaminated pots than in control samples. Conversely, the citric acid concentration was the lowest $\left(<0.5 \mathrm{mg} \mathrm{L}^{-1}\right)$ and succinic acid the highest ( $5 \mathrm{mg} \mathrm{L}^{-1}$ ); however, their behaviour patterns were similar with higher production in treatments without pesticides than in contaminated pots. Oxalic acid was significantly $(p<0.05)$ higher in contaminated pots at day 30 compared with the control without pesticides, and its production increased during the incubation period in both treatments. Significantly $(p<0.05)$ higher malic acid production was detected all over the time in pesticide treatments than in the 

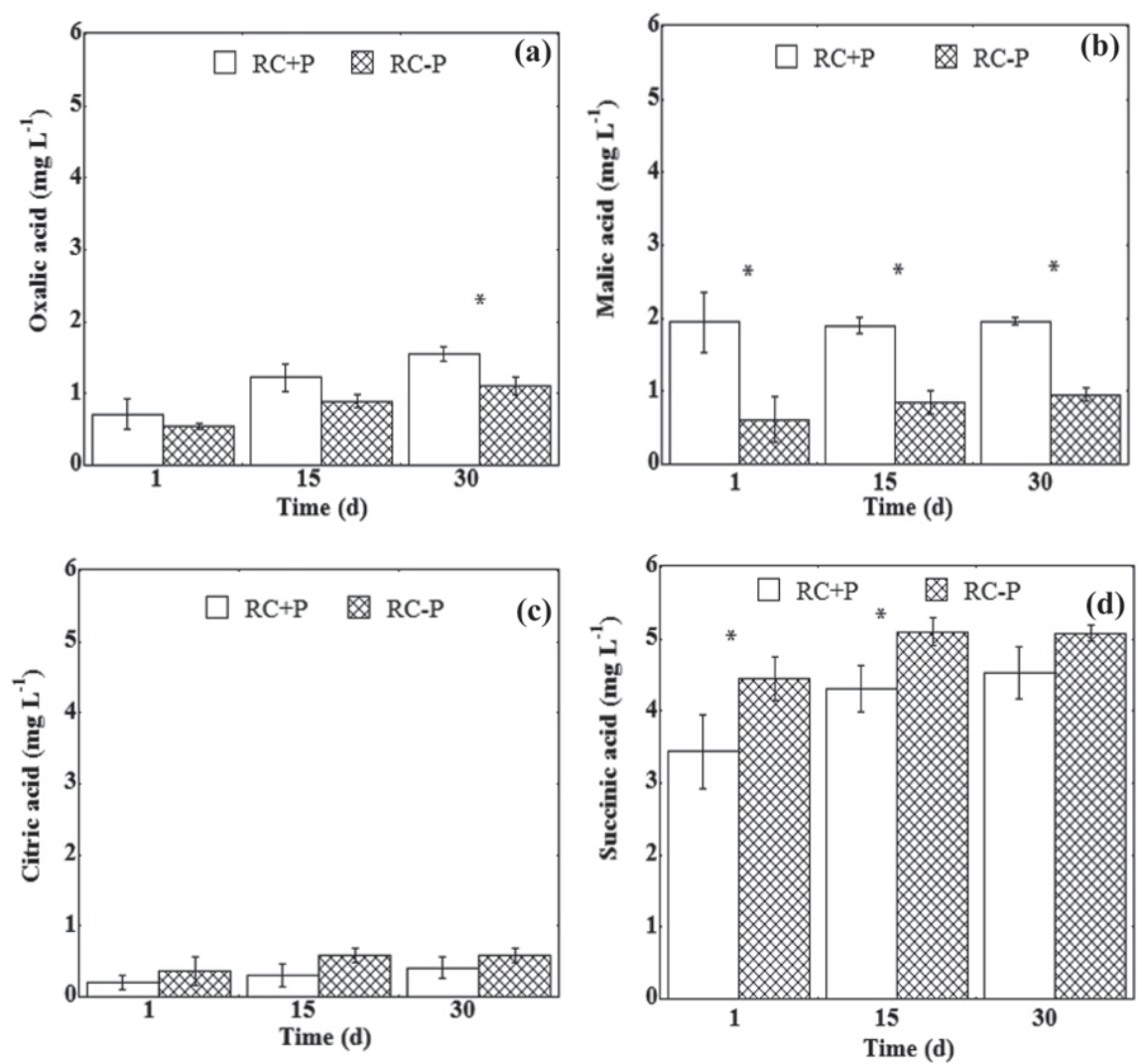

Figure 4. Root exudation of oxalic acid (a), malic acid (b), citric acid (c) and succinic acid (d), under pesticide mixture contamination (ATZ, CHL and ISP at $5 \mathrm{mg} \mathrm{kg}^{-1}$ ) and control treatments without pesticides, during the incubation time. Each value is the mean of three replicates with error bars showing the standard deviation of the mean. * refer to significant differences in mean values between contaminated and non-contaminated treatment on the same day (Student's t-test, $p<0.05$ ).

control, and its production was more than double compared with the pots without pesticides.

Organic acid exudations depend on several environmental factors and are involved in many soil and plant processes, such as mobilization and nutrient uptake by plants and microorganisms, detoxification of metals by plants, microbial proliferation in the rhizosphere and dissolution of soil minerals (Ryan et al., 2001). It is difficult to determine the role of these specific organic acids in ATZ, CHL and ISP dissipation; however, our results demonstrated that oxalic acid and malic acid concentrations were higher in response to pesticide contamination. Root exudates, particularly oxalic and malic acids, are capable of chelation, which is related to phenoloxidase stimulation including $\mathrm{MnP}$ because organic chelators, such as oxalate and malate, produced by ligninolytic fungi (e.g., white rot fungi) can stabilize $\mathrm{Mn}^{3+}$ and thereby stimulate lignin-degrading enzyme activities (Hakala et al., 2005; Marco-Urrea and Reddy, 2012). 
These organic acids could therefore be involved in the enhanced oxidation of the pesticides in planted pots. The above is related to the increased fungal population that was observed in the rhizosphere of the compartment with the pesticide addition (Figure 3a). Walton et al. (1994) demonstrated that plants can respond to chemical stress by increasing radical exudation, which affects rhizosphere microorganism composition or activity and enables them to degrade toxicants.

Our results demonstrated that pesticide contamination caused slightly negative effects in citric acid exudation at all days of the assay and succinic acid exudation at day 30. Moreover, significant decreases $(p<0.05)$ were observed in succinic acid exudation at day 1 and 15 compared with the control. These findings suggested that root exudation of organic acids changed with pesticide contamination. Similarly, Wang et al. (2014) reported that succinic acid and lactic acid exudation in the rhizosphere of mangrove plants enhanced mixed polycyclic aromatic hydrocarbon (PAH) removal in contaminated sediment compared with unplanted control. B. gymnorrhiza had significant positive correlations between lactic acid and PAH contamination levels, while citric acid revealed significant negative correlations with PAH levels in two other species $(K$. obovata and A. marina). They suggested that organic acid exudation changed PAHs contamination and different plant species.

\section{Conclusion}

The rhizosphere effect significantly enhanced atrazine, chlorpyrifos and isoproturon dissipation in an organic biomixture. The largest and most rapid loss of pesticides in the planted pots was in the root compartment followed by the root-free compartment due to microorganism and root exudate transfer between compartments. The enhanced pesticide dissipation was accompanied by an increase in oxalic acid and malic acid exudation concentrations, which induced lignin-degrading enzyme activities (phenoloxidase activity). Moreover, a high relative abundance of fungal and bacterial population was detected. Our results demonstrated that the grass layer is a significant positive factor for promoting pesticide removal in the biobed system.

\section{Acknowledgments}

This work was supported by FONDECYT project $\mathrm{N}^{\circ}$ 1120963, CONICYT/FONDAP/15130015, CONICYT-21110405-2011 doctoral support scholarship, CONICYT-24121122 thesis support scholarship, BECAS CHILE-75120104-2012 doctoral internship and by the Spanish Science and Innovation Ministry and co-financed with European funds through the project (CTM2010-16807).

\section{References}

Berg, G. Smalla, K. 2009. Plant species and soil type cooperatively shape the structure and function of microbial communities in the rhizosphere. FEMS Microbiol Ecol. 68, 1-13.

Briceño, G., Palma, G., Duran, N. 2007. Influence of organic amendment on the biodegradation and movement of pesticides. Crit Rev Env Sci Tech. 37, 233-271.

Castillo, M.D.P., Stenström, J., Ander, P., 1994. Determination of manganese peroxidase activity with 3-methyl-2-benzothiazolinone hydrazone and 3-(dimethylamino)benzoica cid. Anal Biochem. 218, 399-404.

Castillo, M.D.P., Torstensson, L. 2007. Effect of biobed composition, moisture, and temperature on the degradation of pesticides, J. Agric. Food. Chem. 55, 5725-5733. 
Castillo, M.D.P., Torstensson, L., Stenström, J. 2008. Biobed for environmental protection from pesticide use - a review. J. Agric. Food Chem. 56, 6206-6219.

Castillo, J.M., Romero, E., Nogales, R. 2013. Dynamics of microbial communities related to biochemical parameters during vermicomposting and maturation of agroindustrial lignocellulose wastes. Bioresour. Technol. 146, 345-354.

Chaudhry, Q., Blom-Zandstra, M., Gupta, S., Joner, E. 2005. Utilising the synergy between plants and rhizosphere microorganisms to enhance breakdown of organic pollutants in the environment, Environ. Sci. Pollut. Res. 12(1), 34-48.

Diez, M.C. 2010. Biological aspects involved in the degradation of organic pollutants, J Soil Sci Plant Nut. 10, 244-267.

Haichar, F.E., Marol, C., Berge, O., Rangel-Castro, J.I., Prosser, J.I., Balesdent, J., Heulin, T., Achouak, W. 2008. Plant host habitat and root exudates shape soil bacterial community structure. ISME J. 2, 1221-1230.

Hakala, T.K., Lundell, T., Galkin, S., Maijala, P., Kalkkinen, N., Hatakka, A. 2005. Manganese peroxidases, laccases and oxalic acid from the selective white-rot fungus Physisporinus rivulosus grown on spruce wood chips. Enzyme Microb. Tech. 36, 461-468.

He, Y., Xu, J., Tang, C., Wu, Y. 2005. Facilitation of pentachlorophenol degradation in the rhizosphere of ryegrass (Lolium perenne L.). Soil Biol. Biochem. 37, 2017-2024.

Hernández-Allica, J., Becerril, J.M., Zárate, O., Garbisu, C. 2006. Assessment of the efficiency of a metal phytoextraction process with biological indicators of soil health. Plant Soil. 281, 147-158.

Lee, S.H., Lee, W.S., Lee, C.H., Kim, J.G. 2008. Degradation of phenanthrene and pyrene in rhizosphere of grasses and legumes. J. Hazard. Mater. $153,892-898$.
Lu, H., Zhang, Y., Liu, B., Liu, J., Ye, J., Yan, C., 2001. Rhizodegradation gradients of phenanthrene and pyrene in sediment of mangrove (Kandelia candel (L.) Druce). J. Hazard. Mater. 196, 263-269.

Marco-Urrea, E., Reddy, C.A. 2012. Degradation of chloro-organic pollutants by white rot fungi microbial degradation of xenobiotics, in: Singh, S.N (Ed.), Microbial Degradation of Xenobiotics: Environmental science and Engeneering. Berlin, Germany: Springer-Verlag. vol. 2, pp. 31-66.

Merini, L.J., Bobillo, C., Cuadrado, V., Corach, D., Giulietti, A.M., 2009. Phytoremediation potential of the novel atrazine tolerant Lolium multiflorum and studies on the mechanisms involved. Environ. Pollut. 157, 3059- 3063.

Moreno, B., Nogales, R., Macci, C., Masciandaro, G., Benítez, E. 2011. Microbial eco-physiological profiles to estimate the biological restoration of a trichloroethylene-contaminated soil. Ecol. Indic. 11(06), 1563-1571.

Muyzer, G., de Waal, E.C., Uitterlinden, A.G., 1993. Profiling of complexmicrobial populations by denaturing gradient gel electrophoresis analysis of polymerase chain reaction-amplified genes coding for $16 \mathrm{~S}$ rRNA. Applied and Environ. Microbiol. 59, 695-700

Neumann, G., George, T.S., Plassard, C. 2009. Strategies and methods for studing the rhizosphere - the plant science toolbox. Plant Soil. 321, 431-456.

Petric, I., Philippot, L., Abbate, C., Bispo, A., Chesnot, T., Hallin, S., Laval, K., Lebeau, T., Lemanceau, P., Leyval, C., Lindström, K., Pandard, P., Romero, E., Sarr, A., Schloter, M., Simonet, P., Smalla, K., Wilke, B.M., Martin-Laurent, F. 2011. Inter-laboratory evaluation of the ISO standard 11063 Soil quality - method to directly extract DNA from soil samples. J. Microbiol. Methods. 84, 454-460. 
Read, D.B., Bengough, A.G., Gregory, P.J., Crawford, J.W., Robinson, D., Scrimgeour, C.M., Young, I.M., Zhang, K., Zhang, X. 2003. Plant roots release phospholipid surfactants that modify the physical and chemical properties of soil. New Phytol. 157, 315-326.

Ryan, P.R., Delhaize, E., Jones, D.L. 2001. Function and mechanism of organic anion exudation from plant roots. Annu. Rev. Plant Phys. 52, 527-560.

Singh, N., Megharaj, M., Kookana, R.S., Naidu, R., Sethunathan, N. 2004. Atrazine and simazine degradation in Pennisetum rhizosphere. Chemosphere. 56, 257-263.

Strobel, B.W. 2001. Influence of vegetation on lowmolecular weight carboxylic acids in soil solution : a review. Geoderma. 99, 169-198.

Tabatabai, M.A. 1982. Soil enzyme. In: Page, A.L., Miller, E.M., Keeney, D.R. (Eds.), Methods of soil analysis, Part 2, Chemical and microbiological properties, ASA and SSSA, Madison, pp. 907-943.

Urrutia, C., Rubilar, O., Paredes, C., Benítez, E., Azcón, R., Diez, M.C. 2013a. Removal of pentachlorophenol in a rhizotron system with ryegrass (Lolium multiflorum). J. Soil Sci. Plant Nutr. 13(2), 499-510.
Urrutia, C., Rubilar, O., Tortella, G.R., Diez, M.C. 2013b. Degradation of pesticide mixture on modified matrix of a biopurification system with alternatives lignocellulosic wastes. Chemosphere. 92(10), 1361-1366.

Vainio E.J., Hantula, J. 2000. Direct analysis of wood-inhabiting fungi using denaturing gradient gel electrophoresis of amplified ribosomal DNA. Mycol. Res. 104, 927-936.

Walton, B.T., Hoylman, A.M., Perez, M.M., Anderson, T.A., Johnson, T.R., Guthrie, E.A. Christman, R.F. 1994. Rhizosphere microbial communities as a plant defense against toxic substances in soils, in: Anderson, T.A., Coats, J.R. (Eds.), Bioremediation through Rhizosphere Technology, ACS Symposium Series 563, American Chemical Society, Washington, DC, pp. 82-92.

Wang, Y., Oyaizu, H. 2009. Evaluation of the phytoremediation potential of four plant species for dibenzofuran-contaminated soil. J. Hazard. Mater. $168,760-764$.

Wang, Y., Li Lin, L.F., Luan, T., Tam, N.F.Y. 2014. Effects of low molecular-weight organic acids and dehydrogenase activity in rhizosphere sediments of mangrove plants on phytoremediation of polycyclic aromatic hydrocarbons. Chemosphere. 99, 152.159. 